\title{
O REARRANJO DAS REDES SOCIAIS DE PARENTESCO DOS PORTADORES DO HIV
}

\author{
NELSON FELICE DE BARROS
}

BARROS, N. F. O Rearranjo das Redes Sociais de Parentesco dos Portadores do HIV. Semina: Ci. Biol./Saúde, v. 16, n. 2, p. 283-291, jun. 1995.

RESUMO: Um estudo de caso permite generalizações que ampliam as conclusões, obtidas com uma pequena amostra, para o universo dos casos. Certamente, é possivel, a partir desta análise com os portadores do HIV de Campinas, reconhecer, no geral, como as redes sociais de parentesco reorganizam-se. Porém, é preciso reconhecer as especificidades dos recortes metodológicos, em relação à familia nuclear, à fase de expansão do ciclo familiar e a possibilidade de reduzir a noção sistêmica das redes sociais, para a análise de subpartes, que constituem as redes sociais de parentesco. A observação permitiu reconhecer, em qualquer formato de rede, os diferentes niveis de respostas e as opçסes elaboradas, pelos portadores do HIV, para manterem os laços, que também representama manutençăo das trocas de bens materiais e senviços, de suas redes sociais de parentesco.

PALAVRAS CHAVE: AIDS, Familia Nuclear, Ciclo Familiar, Redes Sociais e Redes Sociais de Parentesco.

\section{1-INTRODUÇÃo}

Para alguns, vivemos a continuidade da modernidade; para outros, a rapidez do acesso à informação e às imagens fundam a pós-modernidade. Em outro campo do conhecimento, a doença continua sendo o desequilíbrio da homeostasia, porém é também uma construção sócio-cultural. Neste contexto de diferentes compreensões da realidade, apresenta-se a Síndrome da Imunodeficiência Adquirida com a velocidade das trocas de informações, integrando a pósmodernidade, mas no bojo dos velhos tabus que a modernidade questiona e reconhece como culturalmente construído nas sociedades que adentra.

Trabalhar com AIDS é ter uma perspectiva inesgotável de temas. Além da singularidade de cada área de conhecimento, pois as análises podem privilegiar as dimensões econômicas, sociais, políticas, médicas, tecnológicas e outras, há também o universo de desdobramentos de cada área. Assim, novamente privilegia-se a fragmentação do homem ao diferenciá-lo em portador do vírus (sintomático, assintomático etc), criando-se os guetos culturais que propiciam a construção de campanhas específicas e atenção direcionada a grupos específicos, além da inevitável construção social do estigma.

Este artigo é a resultante de um trabalho com um grupo de 30 soros positivos, com os quais foi desenvolvida uma convivência, ao longo de dois anos (1992-1993), para então elaborar uma análise com apenas sete (07) pessoas do conjunto. Fato que mostra, inexoravelmente, os recortes metodológicos desenvolvidos no universo do grupo.
O primeiro recorte foi espacial. Logo, tratou-se de trabalhar com soros positivos da cidade de Campinas, mas apenas os que freqüentavam as manhãs de terças-feiras do Ambulatório de Moléstias Infecciosas do Hospital das Clínicas da Unicamp, ou que recebiam algum tipo de assistência da AGAEVI (Associação Grupo de Apoio Esperança $e$ Vida), que desenvolve sua ação na forma de uma ONG. Assim, de acordo com a nomenclatura desenvolvida para tratar com os portadores da Sindrome, o trabalho foi desenvolvido com sintomáticos (aqueles que já sofreram algum tipo de intervenção médica curativa em decorrência de alguma infecção oportunista).

O segundo recorte pretendeu delimitar no grupo, os portadores com relações conjugais, ainda que tais laços tivessem sido rompidos com a evidência da Síndrome. De forma que a especificidade metodológica desta escolha buscou previlegiar familias nucleares em sua fase de expansão do ciclo familiar.

Inicialmente, a perspectiva era analisar familias com apenas um dos cônjuges portando o HIV, porém ao longo do período de convivência roi possível notar um aumento crescente de casais portadores em busca de tratamento. Desta evidência, resultou o acréscimo de casais nesta análise. Esta mudança ao longo do desenvolvimento do projeto, não acarretou qualquer quantidade de perda, pois o objetivo de compreender como se reorganizam as redes sociais de parentesco passa tanto pelos núcleos que operam com os dois cônjuges portando o HIV, quanto com os grupos de apenas um dos cônjuges.

De fato, a mudança mencionada colocous o projeto no modelo inicialmente desejado, ou seja, permitiu que

- Pós-graduando do Departamento de Medicina Preventiva e Social da Faculdade de Ciências Médicas da Unicamp. 
a partida fosse dada por pressupostos, os quais, diferentemente de hipóteses, possibilitaram um perfeito exercício de reses e antíteses na busca da compreensão do fato analisado. Atingiu, portanto, o formato de uma análise antropológica, que executa a relativização, à medida em que a observação simbólica entre pesquisador e pesquisado sofre um processo de desconstrução em sua forma mais dura de operar com os métodos da ciência, para assumir uma forma mais coloquial e portanto reconstruída entre os interagentes.

O trabalho, também, procurou analisar as representações pessoais do estigma e do momento continuado de uma crise, no qual os valores e comportamentos são reavaliados, passando por um processo de desestruturação em busca de uma nova estrutra que comporte a sobrevivência com o HIV. Nesta medida, a perspectiva antropológica beneficia-se, sobremaneira, por operar com metodologias microanalíticas. Porém, não perde de vista a auto-crítica em relação aos limites do seu alcance analítico, já que não permite a generalização do fato em evidência, muito embora reconheça o trâmite das relações do nivel específico em direção ao geral e vice-versa.

\section{2-O ESTUDO SOBREFAMILIA}

O estudo da família nas Ciências Sociais brasileira remonta às primeiras décadas deste século com os trabalhos de Gilberto Freyre. Naquale contexto sócioeconômico, principalmente no nordeste, local onde o autor desenvolve seus estudos, predominava a organização familiar de estrutura extensa, ou seja, famílias que cohabitavam em mesmo espaço, mas com a temporalidade demarcada pela convivência de duas, ou mais gerações.

As produções com os conceitos de familia extensa predominam enquanto as temáticas suscitadas pelo processo da urbanização não se encontram fundamentadas, pois, na medida em que os trabalhos nas cidades, principalmente pautados na corrente funcionalista parsoniana, vão sendo formulados, as conceituaçôes sobre famillia vão passando por mudanças, até serem caracterizadas como familia nuclear.

A familia nuclear é analisada sob duas perspectivas: uma, que a caracteriza como instituição mantenedora da ordem social, justamente por sernela que ocorre a fase de socialização e reprodução dos valores sociais desde a infância; e a outra, que parte da perspectiva marxista para considerá-la uma estrutura pequeno-burguesa em vias de extinção. Todavia, qualquer que seja o ponto metodológico de partida, as características da familia nuclear são tratadas de forma consensual, entre seus estudiosos, na medida em que é reconhecida em sua constituição como um núcleo habitado apenas pelos pais e filhos; por sua autonomia econômica e inserção na macroestrutura do mercado; pela sua pouca importância no poder político total; pela sua pequena influência na integração da sociedade mais ampla; por não se constiúuir referência na constituição do parentesco extenso; pela independência econômica dos filhos e a consequiente redução da autoridade patema; pela participacăo da mulher no sistema produtivo resultando numa diminuiça da assimetria de status entre os cônuges; por uma sîuacão de natalidade planejada e reduzida e pela racionalização das relações conjugais através da legislaçăo juridica do matrimônio.

Os trabahos de FAUSTO NETO (1982) e BILAC (1978) foram produzidos na perspectiva de compreender como são desenvolvidas as estratégias de sobrevivência de familias de trabathadores unbanos de bairros de baixa renda. Sua anáilise esteve pautada na utilização de conceitos de classe social e trabalho. Este artigo parte da mesma perspectiva de compreender a maneira como se organiza a familia em suas ações de sobrevivência, no entanto, em um momento estrito de crise. A semelhança, com as análises acima citadas, está em concordar que a famillia é a primeira instituiçào a ser mobilizada no momento em que alguns fatores a colocam em risco de sobrevivência. Já a dissemelhança em relação às obras, está no fato de que este trabalho não desenvolve uma análise fundamentada na noção de classe social, mas tendo como recorte a presença de pelo menos um portador do HIV na familia. A crítica a esta opção está explicita na razão de que trabalhar a familia sem caracterizá-la economicamente significa descontextualizá-la socialmente, porém a justificativa está no fato de que lodos os entrevistados eram constituintes de familias expostas ao fator de máxima estigmatização social do contexto. Assim, a perspectiva de análise é também social, porém menos econômica e mais simbólica, em relação 20 que possa representar a AIDS e sua construção social.

Houve a necessidade de um segundo recorte na operação do conceito de familia. Trata-se de diferenciar o potencial da instituição familiar em suas diferentes fases. Em outras palavras, existe um potencial intrínseco a cada membro da familia nuclear, do qual depende sua própria sobrevivência enquanto núcleo. Durante o ciclo de vida de uma familia é possivel identificarem-se três grandes momentos: a fase de expansão, que vai desde o casamento até a completa formação da familia de procriação e corresponde ao periodo, durante o qual, bodos os tithos do casal têm relações de depencência econômica, afetiva e juridica com os pais. O segundo momento é denominado de fase de dispersão ou cisão e prolonga-se do inicio da fase adulta até o casamento do ủt timo fitho do casal, os quais conformaram suas familias nucleares. Oterceiro momento é o de substituição da ramilia que culmina com a morte dos pais a reposiça na estrutura social de sua familia pela de seus filhos.

Como dito acima, o estrdo privilegiou a fase de expansão do ciclo familiar enire os sujeitos pesquisados, deixando evidente o recorte metodológico que reduziu em apenas 07 os casos analisados no trabalho, pois em Campinas há uma relação de quatro (04) homens para cada (01) mulher ponando o HIV e em fase de tratamenio. Porém, sabido que o risco de contaminação por relaçőes sexuais é muiro distinto entre 
os sexos -segundo estatísticas a proporção de risco é de dezesseis (16) vezes maior para as mulheres-, de forma que o predominio de homens quer significar a prevalência, ainda e de forma decrescente, de homossexuais no coletivo dos portadores de Campinas. Há, também, predominância da faixa etária entre 20 e 40 anos, fato que acaba situando a maioria dos portadores, quando casados, em familias na fase de expansão do ciclo familiar.

Apenas como curiosidade, ou notas de observações paralelas, pude perceber a temática de uma outra forma de análise em relação à famillia. De fato, é possivel elaborar um estudo familiar com casais homossexuais, pois estes constituem familia nuclear e mesmo extensa, porém com sua forma própria de organização e comportamento, além, logicamente, da ausência de filhos consangüineos.

\section{3-O USO DAS REDES SOGIAIS}

Na história das Ciências Sociais, desde sua gênese, houve uma pernanente preocupação de explicar os fatores, fundamentais e determinantes, das organizações sociais. Se por um lado, a sociologia partiu para explicações dos niveis macro, por outro a etnografia optou por análises micro da dimensão social, porém esta opção deveu-se às próprias caracteristicas de seus objetos de análise, pois as comunidades indigenas em sua maioria organizavam-se, ainda organizam-se, em dimensões reduzidas em relação ao número de participantes.

Uma das temáticas mais exploradas foram as relações de parentesco, pelas quais foram analisadas as formas de casamento, a formação de grupos consangüineos a responsabilidade pela criação da prole e o papel do grupo nas condutas individuais. Nessa medida, tomou-se necessário reconhecer as formas que as redes sociais comportavam em cada grupo, em relação aos membros da comunidade analisada e dos membros dessa comunidade com as outras com quem mantivessem relações. Porém, utilização desta metodologia em aldeias indigenas, ou pequenas comunidades rurais, deixou de ocupar a primazia entre outras metodologias, devido ao fato de que a estrutura de tais agrupamentos era bastante reduzida. Assim, a reflexão que EVANS-PRITTCHARD (1937) elabora com as redes sociais, no estudo de parentesco em sociedades tribais africanas adquire dimensão relevante na metodologia antropológica, pois influencia o desenvolvimenio do drama social para as análises em aldeias e pequenas comunidades, assim como o uso das redes sociais em análises de comunidades urbanas.

No desenvolvimento de estudos sobre parentesco em centros urbanos, foi retomada a utilização das redes sociais. A equipe mulidisciplinar em que BOTT (1976) se associa, desenvolve sua análise com familias londrinas, na década de 50. Para a autora, as redes sociais podem ter dois fomatos fundamentais. Trata-se dos formatos de redes sociais frouxas e das redes sociais estreitas. Para elaborar lais conceitos parte-se dos papéis conjugais entre os membros do casal e analisa-se a foma como os conjuges organizam sua convivência em relaça a cos cidolos con a residencia, a divisão de tarefas em relaço 20 S finhos, mannenca econômica do lar, as fomas de diversago, lazer c lomada de decisões.

Há casais que se organizam paniciparivamente em rodas essas dimensões e constinten a pomn dos papéis conjugais conjuntos. Esta opcra lhes grante um pacto que resulta em relaçóes pouco rrequentes aprofundadas fora da vida comum do casal. Cenalmente.

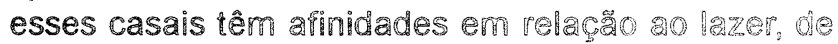
forma que participam de grupos de amizode comum de ambos os conjuges.

Por outro lado, há casais gue se organizan em uma estrurura extremamente assentady naviva social dos papéis sexuais, de foma que às mupheres cobem os encaroos do lar-sua manutenço a aducacaro dos filhos, mesmo que isso implique uma dupla jomada de trabaho- a homem a manu'ençu econonica da familia. Isto inplica comporamentos bastante demarcados em relaça ao lazer, pois, geramente homem diverte-se nas noîes em bares com ourros companheiros que pactum com seus simbolos.

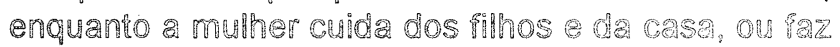
visitas a prentes oue mantem prozinidade geogr:icas e social.

De acordo com os papeis conjugars, seria delneadas as redes Sociais do cosal. Assin pareis

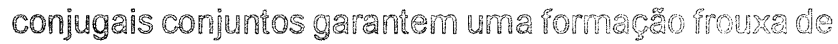
rede social, enguanto os papeis conjugais segrogedos propiciam a organizaça de una rede social estreha.

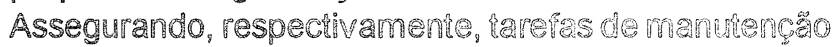
e lazer muiro próximas, no primeiro caso, e muito distintas, no segundo caso.

PaR BARNES (1969), a daboraca do conceilo de rede social passa pelo entendimento de oue "existe uma rede social hotal constiunda por três partes: reole territorial, rede industrial e rede de relagbes: o oue gera justamente uma noção de sistena integrado pellas partes". Mediante esta argnmentaça, o autor obbora uma compatbilizaço do conceiro de rede social con o

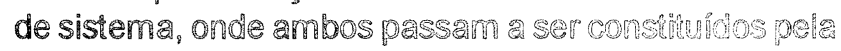
interaça das pares. Argumenta. ando. sobre a possibilidade de un estudo parcial de carda tipo de rede territorial, relacional e industrial- de pomar gue: "por

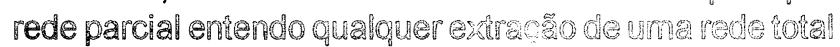

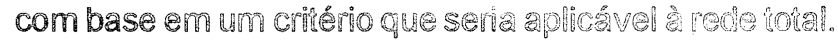
Deste modo, por exemplo, rece cognabica de pareniesco foma uma rede parcial Pabmente iolentificavers (op:27).

Utilizandomos destas reflexues, desenvolvonos a análise das fomas de reorgnizacoes das reces socisis de parentesco, ou seja, desenvolvenos mesn.

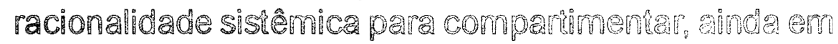
estururas mais reduzidas, as redes de refaces. Tudevir.

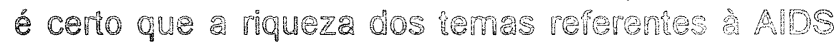
pemitem uma anilise das redes sociais torais, posto que suas dimensōes aningem as relogos sucivis, as

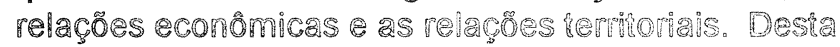


forma, seria possivel efetuar-se uma contextualizaça holística do HUy e seus portadores, porem, também por preferência metodológica, optamos por esta microanálise.

Como intomacoses complementares, gostania de 1ecer comentín as respeito de dois aspecios da relaça entre redes sociais - ADS. O primeiro diz respeito ao papel, fundamental nas relaços de parentesco, do parente conector, reconhecido por BOTT (1976) como uma figura influente canalizadora das mobilizacoses das rocas de senicos 1 infomaços entre os parentes constitnintes da rede de parentesco. 0 segundo aspecto versa a respeilo de un acontecimento histórico ha construço social dis AOS, pois, nos anos iniciais da década de 80. anda quando predominava obscuranismo em relaço sindrome, uma das comprovaçes d: sua hranmissão sexual poi - baoraço da rede social de relacoes, do "Caso zero" e seus parceiros homossexuais com sintomas da Sindrome. pelo sociólogo de uma equipe do seniç epidemiologico noreamemicano (Center of Disease Controls.

\section{A

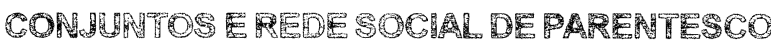 ESTREFTR}

Os condichonares de uma relaca coniugal de papeis coninntos asfar no comparilhamento mútuo irrestrito de larefas de cuidado do lar, manutença econômica do múcleo ramiliar, educaça : \$aũde dos filhos, lazer comparihnado tomada de decisoses efetuadas mediante rrocas de pontos de vista entre os conjuges.

Segundo BOTT (1978:33), mna relaço de pepéis conjugais conjuntos delmira una rede social total frouxa, sendo composta pela dimensão das relaçoses, 1ervitoria - industrial. O que em outras palavras, significa uma união com a participaça integral de ambos os membros nas tarefas, gerando relacionamentos pouco acentuados fora da vida do casal, ou ainda comparihados iguamente pelos conjuges.

A relacia diretamente proporcional entre os papeis conjugais o oipo de rede social daborada pala autora diferenciamse dis nossig duas circunstancias. Por um lado, \$ua elaboraço foi de redes sociais lotais que contemplan as três dimensöes de composiça das redes; por ontro Iado, Poi elaborada cm condiçes nomais durante vida de qualouer casal. Assim, anda que a qualidade dos lagos dos mombros da rede social

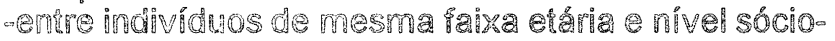
econonnico cunfural aghuturados a individuos de mesmos.

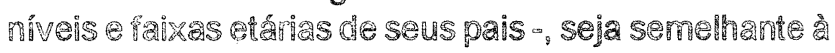
apresenira por BOTT (1978), diferenciam por restringren-Se apenas as relaçes de parenesco e em un complexo nonnento de crise dos valores p papeis sociaำ.

Três, entre os Sete entrevistados, 0 caso" c". constuน - rede social de parentesco estrib, ainda que as caracteristicas de cada caso guardem semelhanças apenas por se tratar de individuos com sorologia positiva para o Hy.

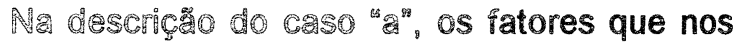

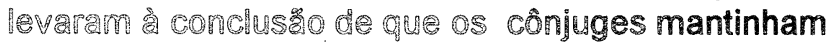
un pspel conjugal conjunto boram: o primeiro, relacionado

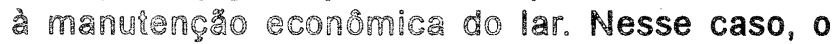
casamento acontecer oundo ambos os cônjuges

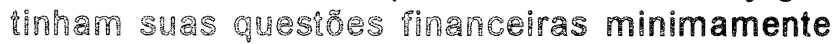
resolvidas, pois ele ocupava um cargo como economista, de acondo com a sua Pomaça, e ela possuia uma clientela Prixa em seu escritorio de advocacia. Assim, 0 montante das rendas era igualmente convertida para a manutença do lar, na foma de uma boa alimentação, aquisição de aparehos aletro-eletrônicos modernos e atendimento total das necessidades da fitha.

O segundo fator foi o do cuidado com a educação - saủde de filna. começr pela opcão de deixála aos cuidados da avó matema-como veremos o parente conechor desta rede social. ate as ocasiones em que a filha necessitava de cuidados médicos, fato de que ambos parill avam a preocupaca. comprometendo-se em marcar (c levar arianç consultas, comprar remédios acompanhah-la durante o tratamento.

Ouanto aos cuidados manutenção do lar.

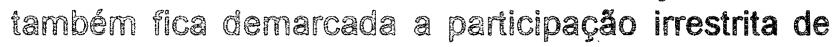
ambos, pois geramente era ele o responsável pela produça das refeico es notumas, enquanto as compras de viveres eram parthindas a contas de condominio do aparamento, imposios encargos sociais eram pagas por aquele que estivesse mais disponivel no dia de vencimento.

Os untimos dois 1atores são relacionados ao lazer - : Iomada de decisőes. Ambos gostavam das mesmas Tonnas de diversão dos bares notumos, casas de dança e convivio com ramiliares, porém estavam extremamente centrados na vida do casal: assim, mesmo em lugares colerivos, não expandiam suas relações a estranhos. Embora na esteja explicito, desde o lugar a ser frequenen:ado ate methor momento para a concepção

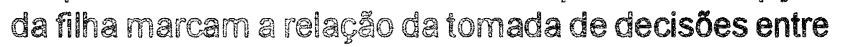
este casal.

Em relaģ : rede social, remos uma forma invers? a a antad pelos estudos de Bot (1976), acima cilados, pois ast? nodelouse com um formato de rede estreira. Neste caso, temos o fator económico funcionando cono aguninador, pois a esposa possuia una sociedade empresarial junto a um imão, também advog300, isto significa que os fatores sociais e cuturais 12mben osiavam em troca na rede social. porm, o hro conector, o qual desempenta o papel de detonador de

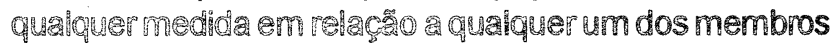
da rede social ao seu redor.

Tanto 0 caso "a". quanto o "b/c" possuem suas redes chrunschensem emo do parente conector; todavia

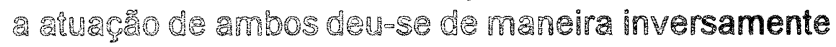
proporcional, na medida em que no caso "a" a mãe da esposa mpenou todos 0 s sus esforcos para eliminar - portador de sua rede, mesmo expondo filha a neta 


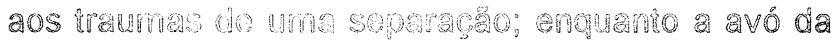

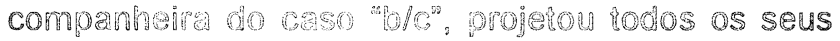

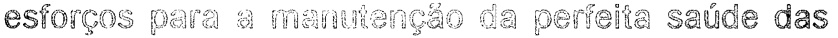

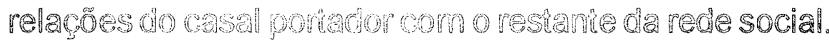

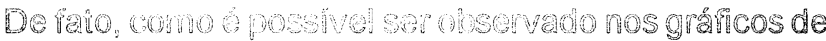

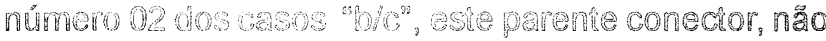

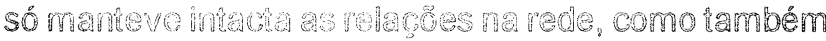

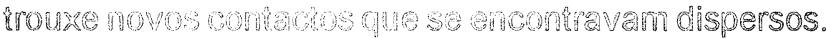

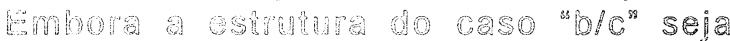

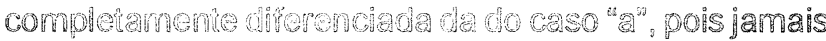

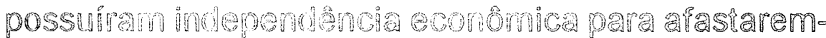

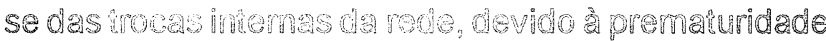

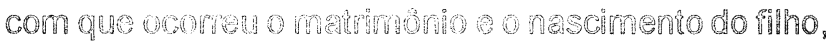
seu nivel de hombon de derispes munca se estendeu

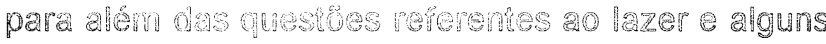

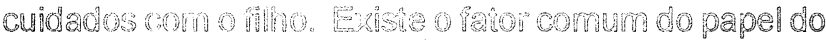
parente conemon, o gual salva co conden a more os

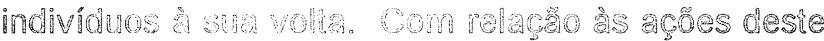

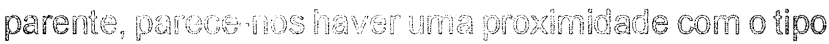

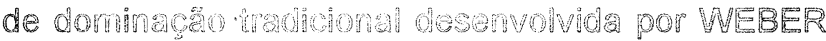

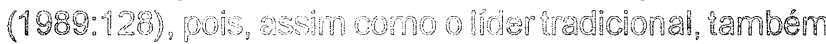

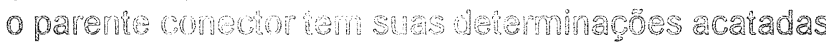

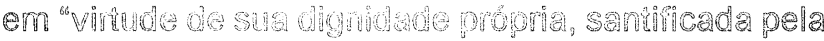

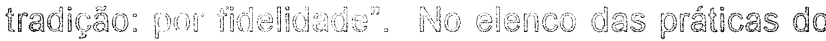

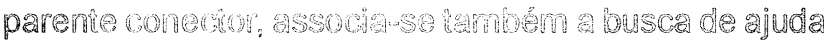

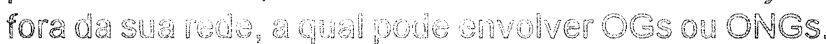

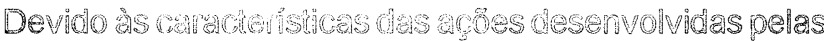

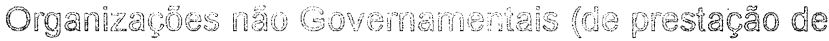

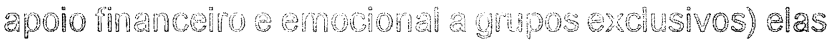

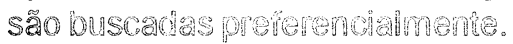

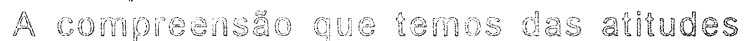
direrenciands uos dois parentes conoctores, remetemnos a questobs Sen respostas no drabsho, porem ricas

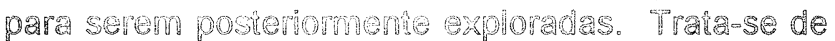

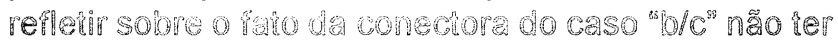
empentovo estorgos para elmoinar o companteiro da

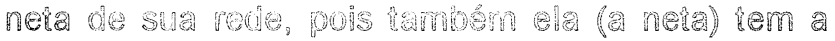

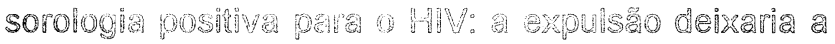

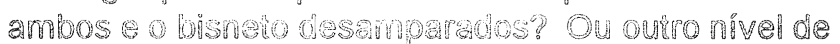

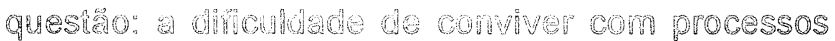

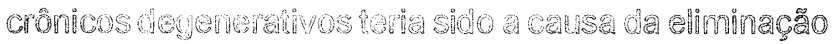
do CaSO "g." de Sua rede, o gnal busca anparo em sua

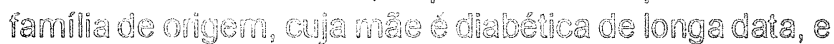
onote acento menementer

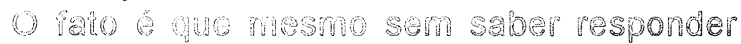

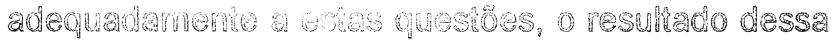

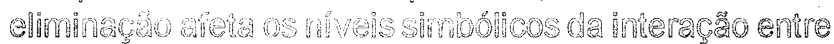

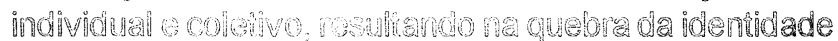

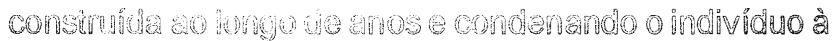

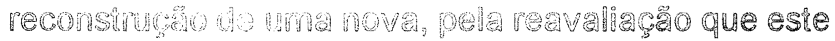

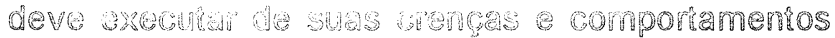

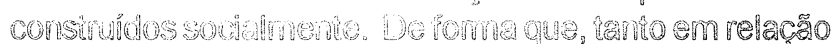

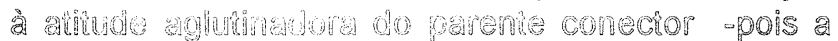

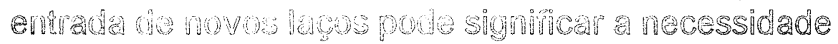

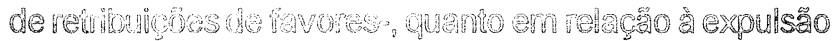

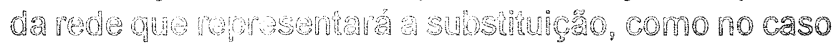

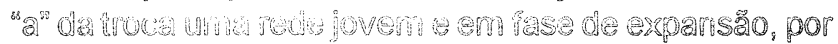

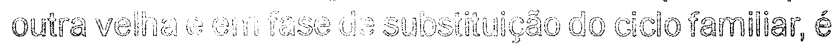

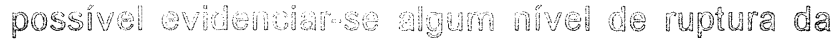

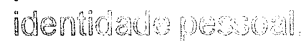

Abaixo seguem as representações gráficas dos casos "a" e "b/c", dispostos de forma a permitir a contraposição dos momentos anteriores e posteriores ao reconhecimento da presença do HIV.

GRÁFICO 1 DO CASO "a"
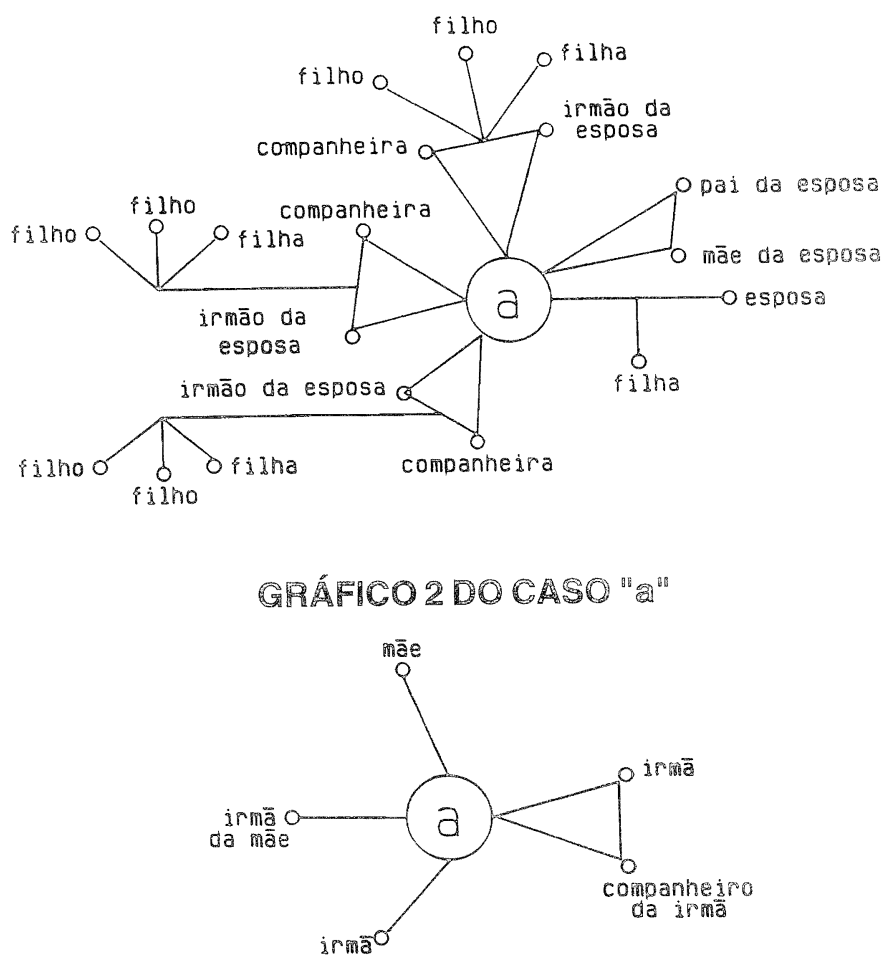

da mae

$$
\text { GRAFICO } 1 \text { DO CASO "b" }{ }^{\text {"G: }}
$$

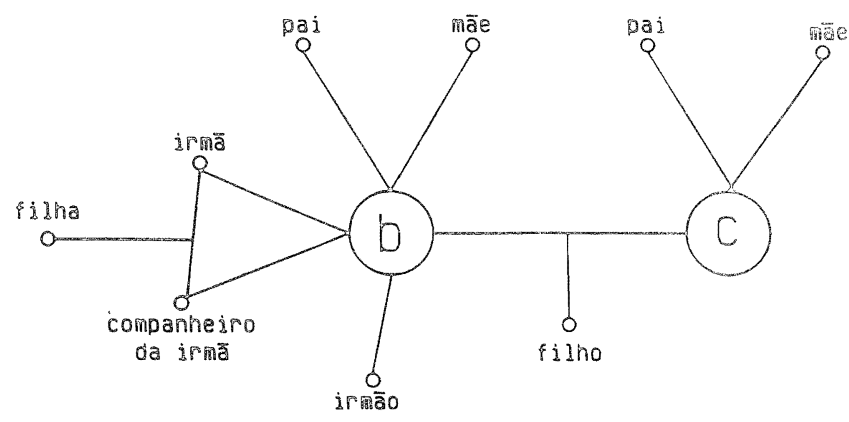

GRAFICO2 DOCASO "B"

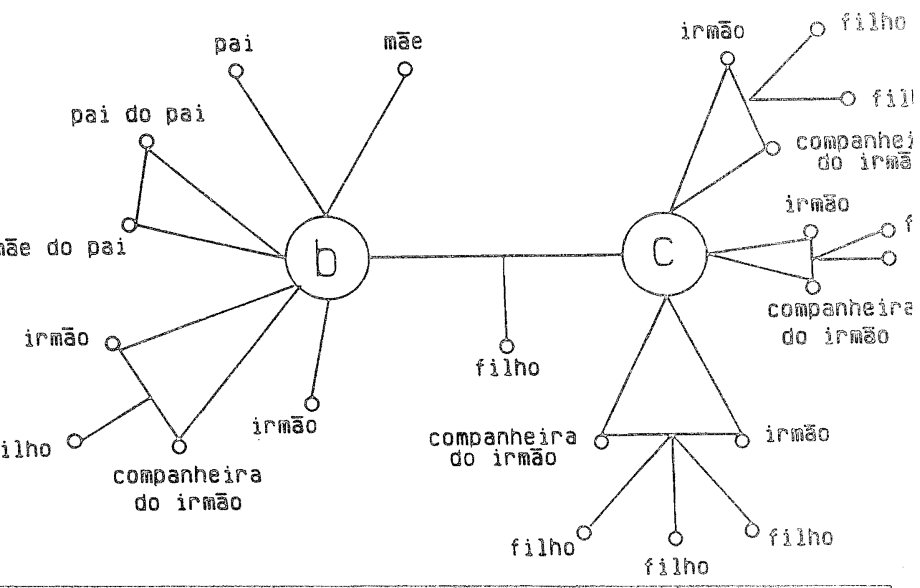




\section{5 - FAMILIAS COM PAPÉIS CONJUGAIS SEGREGADOS EREDE SOCIAL DE PARENTESCO FROUXA.}

Geralmente, casais que se organizam sob uma forte divisão sexual do trabalho, quase nunca dividem momentos de lazer, nem as tarefas de manutenção do lar e nem a educação dos próprios filhos. Nessa estrutura, cabe ao homem, Pundamentalmente, a manutenção econômica da Ramilia, permitindo-fhe um envolvimento minimo com as questões cotiolianas da limpeza, pequenos reparos do lar e com saide educação dos filhos; porém, ̀̀ muher do casal, cabe receber a quantia dada pelo marido e distribuhi-la para a alimentação, vestuário, saúde etc. Nessa medida, existe a rede dos homens, fomada por companheiros de bares, jogos de carta e bilhar, os quais as mulheres nem conhecem; e a rede das mulheres, geralmente formada por outras mulheres familiares, onde ocorrem irequentes ajudas e trocas de bens e serviços.

Nos casos apresentados abaixo, veremos que hi: uma proporça inversa entre a relaça conjugal segregada a formação da rede social, pois a distância entre os cônjuges deveria estar propiciando fortes laços extra-conjugais. No entanto, o momento de crise continuada pela presença do HIV, propiciou formaçőes frouxas nas trocas de bens e infomações darede social de parentesco.

Neste grupo, encontram-se as quatro entrevistados restantes, de forma que constituem os casos "d", "e/f" e "g". Entre as mulheres, três dos quatro membros, existe um padrão em relação ao cuidado com - lar e com a familia, pois todas tinham por obrigaçōes diárias a produção de refeições e conseguiente limpeza. dos utensillios, conservação e pequenos consertos da casa, cuidado com a saúde e alimentação e educação diária dos filhos. Todas estas obrigações acabam significando a dupla jornada de trabalho feminino, pois, por uma questão de necessidade acabam prestando algum tipo de servico fora de casa. Outra característica comum entre as mulheres, são as pequenas trocas de serviços na rede. Geralmente referem-se ao cuidado das crianças, enquanto as outras fazem a limpeza da casa. ou compras de viveres, assim como pequenas incursões como levar à escola, ou ao centro de saúde, etc.

Entre os três casos, existem estruturas de vida diferenciadas. Primeiramente porque se irata de unn casal e de dois casos que passaram por separaça conjugal. Entre os dois uhthmos casos existe o fato de terem passado por dois relacionamentos matrimonias. resultando em mais de um ritho por casamento. Como será possivel evidenciar, tentamos elaborar as díerentes redes sociais familiares que essas pessoas constiuniram. de forma que o caso "d" possui três graficicos que the demarcam os casamentos a a fase atual. Nesse caso. existem caracteristicas proprias em relaça aos papås conjugais, diferenciados para cad relaça, na formação da rede social ramiliar, pois a estutura de sua rede apenas constiuniu-se em tomo de Sur fambia de referência recentemente, quando sua mãe æssume o papel de parente conector, com a intença de viabilizar as açöes em torno do portador do virus.

No caso "g" existe um fator que deve ser notado no grẩico, o qual é de extrema importância na medida em que muinos port3orores optam por desenvolver as ações semelhantes. Como é possivel verificar, sua rede social familiar não passou por qualouer modificação, tanto no primeiro como no segundo natrimônios, porém essa invariabiliodade acontece mediante o isolamento do portador de sua rede. Nesse caso, 0 portador deixou sua rede e parte da familia. (duss filhas) na cidade de São Paulo apenas em datas multo especiais visitava seus pares. Durante essas visitas, quando era questionada em relaçăo seu emagrecimento súbito, afimava tratar-se de um problema no aparelho digestivo eque vinha manterdo-se em iratamento.

Desses quatro casos existem algumas questöes relevantes comuns namedida em que polarizaram-se em opços distintas, devido 20 fato de se depararem com a inseguranç em relaça à possibilidade de retomar e receberem ajuda da rede, on que os excluira em algum momento, ou que jamais existira enquanto núcleo viabilizador de lrocas de bens e serviços. A polaridade é dada pelas escohns desemolvidas em cada caso. Frente a lal dimensão o caso " $Q$ " preferiu ocultar sua Sindrome manter intactos os lacos da rede, pensando em preservá-los para que cuidassem, posteriori, de suas filhas. dá caso "d", age de forma inversa e tenta reelaborar os laços de uña rede social de parentesco, com o apolo de sua mãe, com o fim de conseguir apoio emocional, financeiro e de serviços para o seu tratameno. Também, para o caso "d", existiu a preocupaço de reaproximar-se da familia de origem, para que seus fillos fossem amparados tanto durante o tramamento, quanto no futuro desconhecido de seu falecimento. Porém, e caso "elf" que sofre os maiores problemas com seus pares na rede, pois logo que se casaram, romperam os lacos com os parentes e partiram em busca de constiúuirem seu próprio núcleo familiar. Com o passar dos anos as filhas cresceram e passaram a frequientar a mesma escola que suas primas, fazendo com que, pouco a pouco, fossem sendoreromados os laços da rede de parentesco. Contudo, no momento em ore detecham o pone do Hu, hiveram recrudescidas as relaçes de evínmento na rede. gerando assim um abandono quase completo pelos seus pares. Não há indicios de que a rede de parentesco vô responsabilizarse pelas fihas, porém o casal vem heniando culivar os pequenos laços restantes, como mostra o grático, pois peocupa- hes a longevidade nodefnida.

Certamente, o fato de estar portando HV funciona como um "conte lento e propundo" nas concepcoses existenciais da subjetividade de cada individuo, de forma que o estritamente materialista reconhece-se também espirivushista. o solíário mostrase solidario; 0 ímido, em esplendor de expansão e o alegre, profundamente uriste e deprimido. . De roma que as ourstoes minimas passam a povor objetivamente a via, a as precupacos com os que hes cercam arophismese. 
Muitas de suas representações podem ser reconhecidas nos gráficos dos momentos anteriores e posteriores, de forma que no caso "d" reconhece-se a pequena variação, porém significativa, por passar a ser uma constituição de sua família de origem e exigir novos papéis sociais para cada membro -sua mãe assume o papel de parente conector. Nos gráficos do caso "e/f" reconhece-se a marca de seu abandono e no caso "g", a perfeita manutenção de seus laços na rede social de parentesco, a partir de sua opção de independência emocional e material.

\section{GRÁFICO 1 DO CASO "d"}

Primeiro Matrimônio

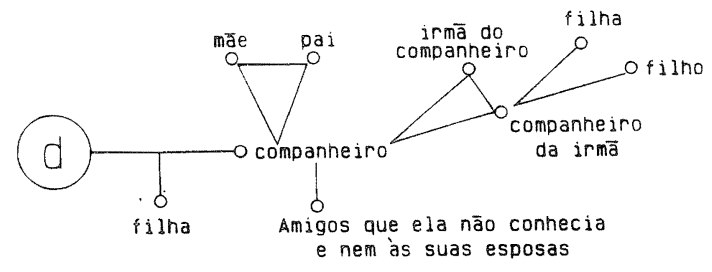

GRÁFICO 2 DO CASO " $d$ "

Segundo Matrimônio

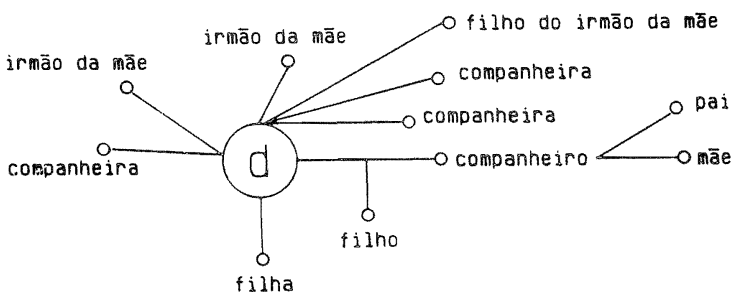

GRÁFICO 3 DO CASO "d"

Agora

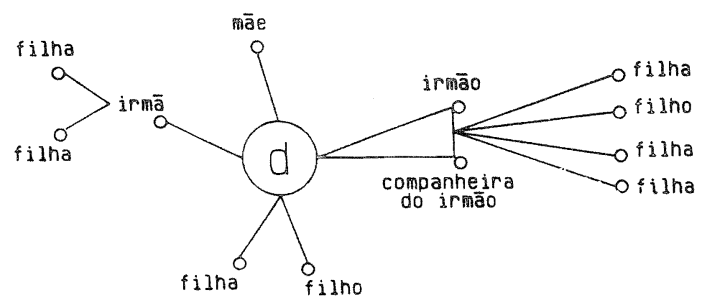

\section{GRÁFICO 1 DO CASO "e" E "f"}

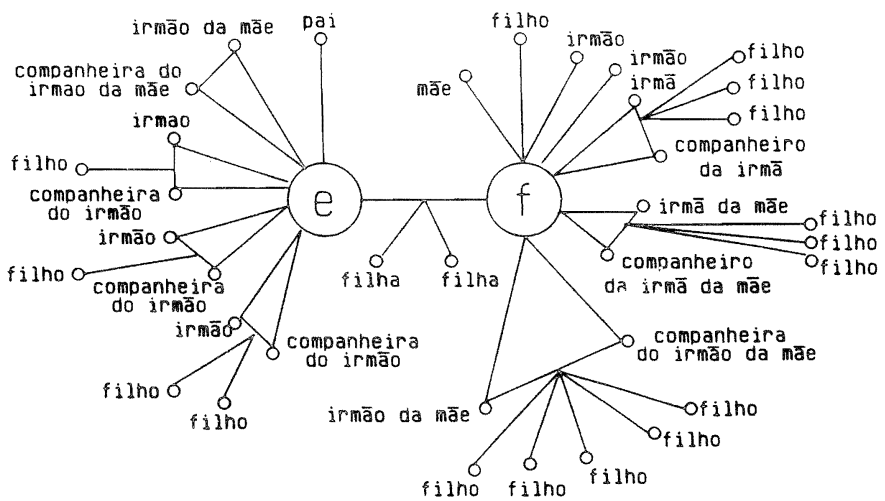

GRÁFICO 2 DO CASO "e" E "f"

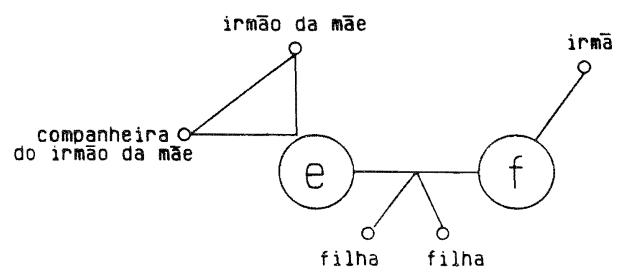

GRÁFICO 1 DO CASO " $g$ "

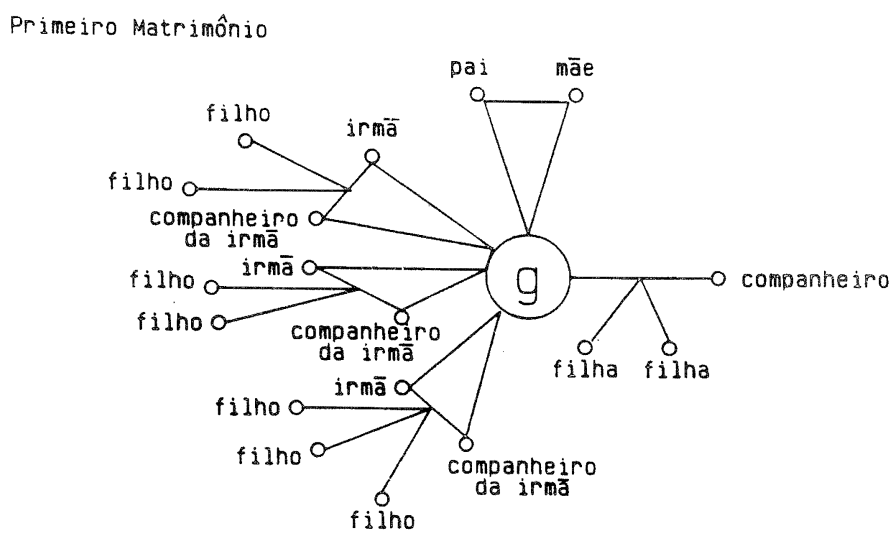

GRÁFICO 2 DO CASO "g"

Segundo Matrimônio

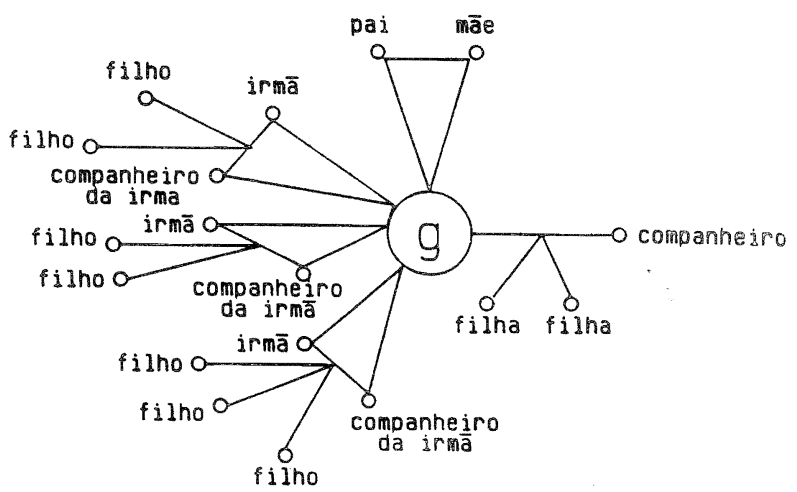

\section{6- CONCLUSÕES}

Fundamentalmente, operamos com dois niveis distintos de conclusões: uma primeira, de cunho teórico acadêmico, e a outra de considerações retiradas do estudo dos casos apresentados, com predominância de interesse na relação da viabilidade dos cuidados nas redes sociais de parentesco e diferentes serviços. Certamente, embora o método do estudo de caso o 
permita, essas considerações não deverão tomar dimensões generalizantes, devido à sua reduzida amostragem e pelas inúmeras concepções do processo de saúde e doença, mediadas pelas crenças e influências dos diferentes aspectos que compõem a vida individual de cada pessoa.

Nessa medida, o aspecto individual é central nessa produção. Primeiro porque é nele que atuam os vários papéis sociais que as sociedades complexas dispõem para cada pessoa; segundo, porque, frente à impossibilidade de tratar individualmente com as macroestruturas sociais, cada ser desenvolve em si as dimensões dos seus níveis de trocas de bens materiais e serviços. Este segundo fator é, também, uma justificativa para a possibilidade de se desenvolverem redes sociais de parentesco, as quais constituem nada além de uma microestrutura que comporta a macroestrutura das redes sociais de parentesco, vizinhança e amizade.

Dessa forma, a argumentação acima conduz-nos à primeira conclusão, a qual quer demonstrar que o desenvolvimento de análises com a metodologia elaborada por BOTT (1976), pode tomar uma outra forma, na medida em que reduz os padrões de análise para níveis ainda menores, em relação aos que compõem a rede social total; em outras palavras, BARNES (1969) demonstra que a noção de rede social é sistêmica, logo constituída por partes, as quais podem ser analisadas individualmente e reduzidas, ainda mais, aos niveis de compreensão de uma rede social de parentesco. Uma vez feita esta microanálise, foi possível constatar-se que papéis conjugais conjuntos podem compor redes sociais estreitas e papéis conjugais segregados compor modelos de redes sociais frouxas, premissa que nos permita afirmar que o modelo de BOTT (1976) explica parcialmente as análises feitas nas subpartes de uma das dimensões que compõem as redes sociais de relações.

Gostaria de apresentar as considerações que compõern o segundo nível de conclusão, a partir de um fragmento retirado de um texto de LEVI-STRAUSS (1970:193-194) escrito em 1949 e que mantém-se completamente atual em relação à AIDS e ao portador do HIV;

"(...) percebe-se mais claramente sobre quais mecanismos psico-fisiológicos estão fundados os casos, atestados em inúmeras regiões do mundo, de morte por conjuro ou enieitiçamento: um indivíduo, consciente de ser objeto de malefício, é intimamente persuadido, pelas mais solenes tradições de seu grupo, de que está condenado; parentes e amigos partilham esta certeza. Desde então, a comunidade se retrai: afasta-se do maldito, conduz-se a seu respeito como se fosse, não apenas já morto, mas fonte de perigo para o seu círculo; em cada ocasião e por todas as suas condutas, o corpo social sugere a morte à infeliz vítima, que não pretende mais escapar àquilo que ela considera como seu destino inelutável. Logo, aliás, celebram-se por ela os ritos sagrados que a conduzirão ao reino das sombras.
Incontinenti, brutalmente privado de todos os seus elos familiares e sociais, excluído de todas as funções e atividades pelas quais o indivíduo toma consciência de si mesmo, depois encontrando essas forças tão imperiosas novamente conjuradas, mas somente para bani-lo do mundo dos vivos, o enfeitiçado cede à ação combinada por intenso terror que experimenta, da retirada súbita e total dos múltiplos sistemas de referência fornecidos pela convivência do grupo, enfim, à sua inversão decisiva que, de vivo, sujeito de direitos e de obrigações, o proclama morto, objeto de temores, de ritos e proibições. A integridade física não resiste à dissolução da personalidade social."

Sem dúvida, essas palavras acima encontrariam identidade perfeita com a realidade do portador do HIV em relação à sua rede social de parentesco e o restante da sociedade, não fosse a atuação das Organizações Não Governamentais. Apresento abaixo as considerações que compõem esta conclusão;

As Organizações Governamentais não apresentam possibilidades de uma nova rede social, ao passo que as Organizações Não Governamentais oferecem esta possibilidade.

Em momentos de crise, em que valores são postos em xeque, quase sempre busca-se ajuda externa às redes sociais de parentesco, pois seus membros também se encontram abalados; estas considerações integram-se de forma complementar e explicativa, pois, nos momentos de crise em que é necessário apoio externo, são as ONGs que desenvolvem este suporte de atenção. Às vezes, as ONGs organizam, até mesmo, atendimento técnico e medicamentoso para os portadores que atende, porém sempre fundamentada em uma prática afetiva e paternalista.

As redes sociais de parentesco, quando informadas do HIV, em um de seus membros, não respondem indiferentemente; quer aglutiando-se para prestar atendimento, quer aglutinado-se para expulsar o menbro portador. De alguma maneira os pares da rede reagem ao HIV, criando um ambiente, no qual o membro doente terá que prestar explicações aos seus pares.

As redes de parentesco de conformação estreita não prestam obrigatoriamente maior apoio ao seu membro portador. Pela proposta desenvolvida por BOTT (1976), em uma rede estreita com laços sociais muito efetivos, era de se esperar que a ajuda também tivesse essa dimensão efetiva e eficaz, porém nossas evidências foram contrárias a esta espectativa.

A ruptura com a rede significa a perda das relações econômicas, sociais e culturais. Mas o rearranjo pode significar aumento apenas das relações econômicas; MAUSS (1928) ao desenvolver as bases das trocas e da dádiva, evidencia o dever que os membros partilham de receber, dar e retribuir os presentes, sendo esta uma das condições de existência das redes sociais. Nos casos analisados, ao que parece, é quebrada esta estrutura, na medida em que alguns antigos pares garantem todo o 
atendimento econômico ao portador, porém desejam que não lhe seja retribuído de forma alguma tal ajuda.

Os papéis conjugais alteram-se de forma diferenciada para ambos os cônjuges, ou apenas um deles, quando portam o HIV; ou seja, é possivel encontrarmos casais unidos e enfrentando o problema, porém é raro evidenciar que o membro não portador permaneça com o companheiro(a) e este Ihe garanta atenção.

Há, em caso de separação do casal, quando se procede à divisão e desmanche do lar, a possibilidade de uma mobilidade física do portador, ou de sua família; esta questão está muito relacionada com o início da epidemia no planeta, quando suas formas de transmissão eram hipotéticas e quando se pensava na Síndrome como fator de ameaça a determinados grupos sociais.

Em casos de pessoas despossuídas, que dependem de seu trabalho para sobreviverem junto com sua família, ocorre mobilidade social do portador quando este passa a receber os benefícios da Previdência Social, referentes à sua aposentadoria; ainda quando os ganhos previdenciários são próximos aos valores dos pagamentos que recebia, torna-se inviável a sobrevivência pelos altos custos do tratamento.

Há aproximação com grupos, religiosos e não governamentais, após a tomada de conhecimento do porte do vírus; em alguns casos, os grupos religiosos são também não governamentais e a aproximação ocorre devido ao fato, já comentado, de que estes grupos estão preparados para prestar uma forma de atenção que se assemelhe aos contactos da rede social de relações.

A conformação de rede social de parentesco estreita comporta um parente conector; o qual tem a característica de um catalisador dentro do grupo e desenvolve suas ações assentado nos padrões de respeito e tradição. Todavia, suas ações podem representar a mobilização para manter a sobrevivência do portador, ou simplesmente, para retrair o grupo e afastar-se do maldito, já considerado morto, conforme as palavras de LEVI-STRAUSS (1970).

O fator cultural traduzido na forma de grau de escolaridade não funciona como facilitador do convivio com o vírus; embora permita decodificar o discurso científico aplicado nos diagnósticos e tratamentos, não assume uma postura definitiva frente ao fato de conviver com o vírus, pois, para reconhecer os processos da vida é preciso que haja uma aliança entre o conhecimento e a sabedoria: é necessário o reconhecimento da objetividade do primeiro, mas também os símbolos naturais do segundo, para sobreviver com a mágica do mistério e a lógica da mágica que resulta no mistério.

Frente ao HIV, poucas famílias assumem toda a responsabilidade da tríade saúde/doença/atenção; principalmente entre os nossos entrevistados, pois estes constituíam famílias nucleares na fase de expansão, momento em que os filhos dependem integralmente dos pais, sendo a solução desenhada na direção da busca de ajuda nas redes sociais de parentesco, ou em organizações que prestem atenção ao portador do HIV.

BARROS, Nelson Felice de. The rearrangement of HIV's bearers relativeness network. Semina: Ci. Biol./Saúde, Londrina, v. 16, n. 2, p. 283-291, Jun. 1995.

ABSTRACT: A case study admits generalizations that extend conclusions obtained with a little sample, for the case universe. It is certainly possible, from the analysis with HIV's bearers of Campinas, to recognize in general the way the relativeness network rearrangment itself. However it is necessary to recognize the specificites of metodological way about the nuclear family, the expansion stage in familiar cycle, as well as the possibility of reducing the system view of the social network for a sub-part analysis, that constitutes the social network of relativeness. The observatiom permited recognize in any kind of network the different levels of answers and the options elaboreted by HIV's bearers to keep the bonds that also represents the bargain support of consomer's goods and services of theirs relativeness network.

KEY-WORDS: AIDS, Nuclear Family, Familiar cycle, Social network, Relativeness neiwork.

\section{REFERENCIAS BIBLIOGRRARICAS}

BARNES,, A. "Network and Political Process": in: Social Network in Urban Situations". (ed.) J.Clyde Mitchell, Manchester, Manchester University Press, 1969, p. $51-71$.

BILAC, E.D. Familias de trabalhadores: estratégias de sobrevivência. São Paulo: Símbolo, 1978.

BotT, E. Familia e Rede Social. Rio de Janeiro:Francisco Alves, 1976.

EVANS-PRITTCHARD, E.E. Witchcraft,oracles and magic among the Aande.Oxiord:Claredon Press, 1937

FAUSTO NETO, A.Q. Famillas Operárias e Reprodução dz Forç de Traabaho. Rilo de daneiro:Vozes, 1982

LEVI-STRAUSS, C. "O Feiniceiro e sua Magia"; in: Antropologia Estrutural. Rio de Janeiro: Tempo Brasileiro, $1970,193.214$.

WEBER, M. Coleção Grandes Cientistas Sociais. (Org.) C. COHN, São Paulo: Ática, 1989. 